\title{
Numerical Simulations of a Diode Laser BPH Treatment System
}

\author{
R. A. London \\ V. Esch \\ S. Papademetriou
}

This paper was prepared for submittal to the

Photonics West' 99 Symposium

San Jose, CA

January 23-29, 1999

February 23, 1999

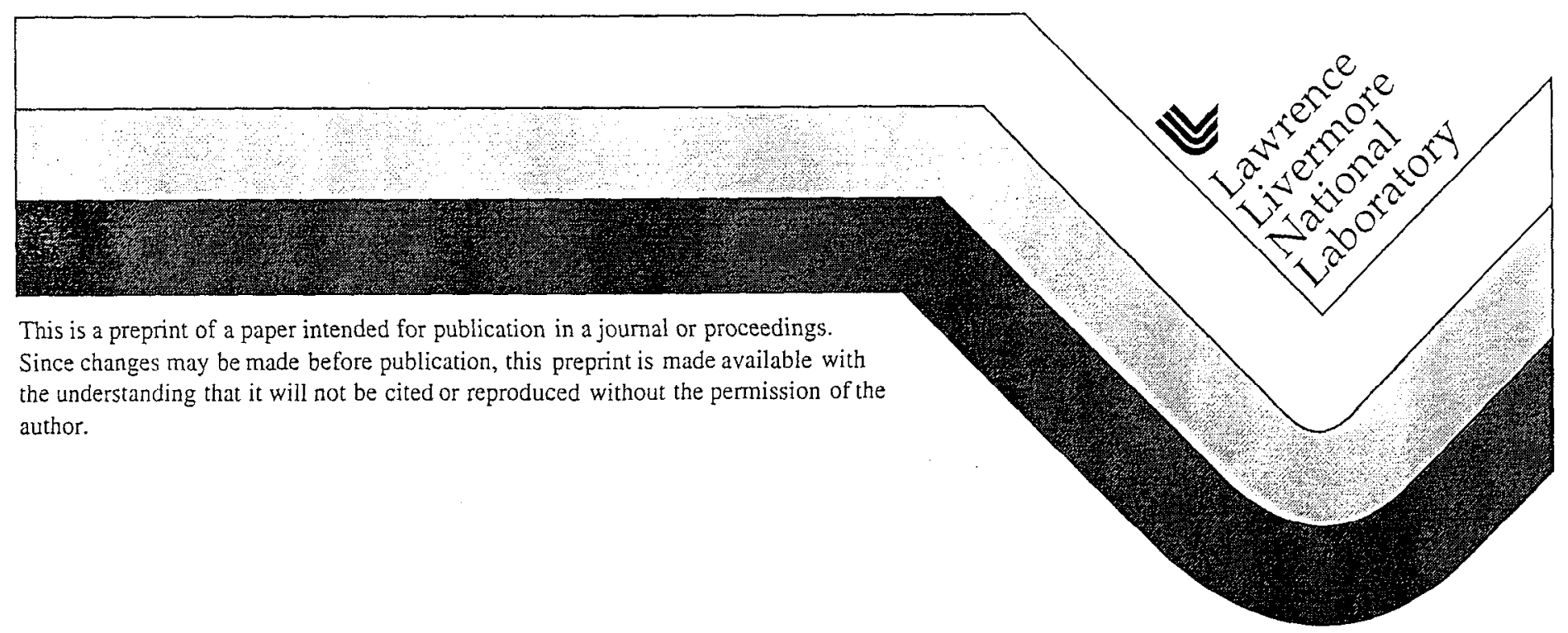




\section{DISCLAIMER}

This document was prepared as an account of work sponsored by an agency of the United States Government. Neither the United States Government nor the University of California nor any of their employees, makes any warranty, express or implied, or assumes any legal liability or responsibility for the accuracy, completeness, or usefulness of any information, apparatus, product, or process

disclosed, or represents that its use would not infringe privately owned rights. Reference herein to any specific commercial product, process, or service by trade name, trademark, manufacturer, or otherwise, does not necessarily constitute or imply its endorsement, recommendation, or favoring by the United States Government or the University of California. The views and opinions of authors expressed herein do not necessarily state or reflect those of the United States Government or the University of California, and shall not be used for advertising or product endorsement purposes. 


\title{
Numerical simulations of a diode laser BPH treatment system
}

\author{
Richard A. London \\ Lawrence Livermore National Laboratory, Livermore, California, 94550 \\ Victor Esch ${ }^{*}$ and Stephanos Papademetriou* \\ Indigo Medical Incorporated
}

\begin{abstract}
Numerical simulations are presented of the laser-tissue interaction of a diode laser system for treating benign prostate hyperplasia. The numerical model includes laser light transport, heat transport, cooling due to blood perfusion, thermal tissue damage, and enthalpy of tissue damage. Comparisons of the simulation results to clinical data are given. We report that a reasonable variation from a standard set of input data produces heating times which match those measured in the clinical trials. A general trend of decreasing damage volume with increasing heating time is described. We suggest that the patient-topatient variability seen in the data can be explained by differences in fundamental biophysical properties such as the optical coefficients. Further work is identified, including the measurement and input to the model of several specific data parameters such as optical coefficients, blood perfusion cooling rate, and coagulation rates.
\end{abstract}

\section{INTRODUCTION}

Benign prostate hyperplasia (BPH) is a pervasive condition of enlargement of the male prostate gland which leads to several urinary difficulties ranging from hesitancy to incontinence to kidney dysfunction in severe cases. Currently the most common therapy is transurethral resection of the prostate (TURP) utilizing an electrosurgical device. Although TURP is largely successful, new BPH therapy methods are desired to reduce the cost and recovery time, improve the success rate, and reduce side effects. Indigo Medical Inc. has recently introduced a new diode laser based BPH therapy system addressing this goal. The development has based on laboratory experiments, animal studies, and clinical trials. The addition of sophisticated numerical modeling can greatly aid in the design of the system and treatment protocol.

* current address: Endovasix, Inc., 298 Harbor Blvd, Belmont, CA 94002 


\section{MODEL DESCRIPTION}

\subsection{Program content.}

We have used the LATIS ${ }^{1}$ computer program to simulate BPH treatments. The name is an acronym for LAser-TISsue interaction. LATIS is a two-dimensional, time-dependent simulation program. It uses cylindrical geometry, with spatial positions described by radial and axial coordinates, $r$ and $z$. Physical properties are modeled mathematically by analytic formulas, table interpolations, and both ordinary and partial differential equations. In addition, the Monte Carlo method is used for laser transport, as described below. The physical processes considered by LATIS are divided into four categories: laser propagation, thermal responsc, material response, and hydrodynamic response. For the present work, we use the Monte-Carlo laser photon transport method, the bio-heat equation, and an Arrhenius model for tissue coagulation. A brief description of the main processes modeled is described here. More details are given in ref. 1.

To simulate the laser light propagation, we use the time-dependent Monte Carlo method, in which light is represented by a finite number of "super photons," each representing many real photons. Henceforth we refer to the super photons simply as photons. A typical BPH simulation uses 100 photons per time step and 500 timesteps for a total of 50,000 photons. Propagation of the photons is treated in a probabilistic manner. They are created along line segments of the numerical mesh with spatial and angular distributions specified to model the diffusing fiber of the BPH system. Fresnel reflection and refraction are calculated as photons cross material interfaces with unequal indices of refraction. Scattering is calculated probabilistically along a photon's path, according to the scattering coefficient, which may vary in space and time. Absorption is calculated analytically along each photon path according to the local absorption coefficient, without destroying the photons.

Absorption of the laser light goes into raising the tissue temperature according to its specific heat, approximately that of water. Heat is then carried away from the laser deposition region by thermal conduction and blood perfusion. This is modeled with the bio-heat equation. We represent the blood-tissue heat exchange with local heating and cooling rates that are linear in the tissue temperature and that drive the tissue towards body temperature: We assume temperature and damage dependence to the blood perfusion described below

We use an "Arrhenius" model, for tissue coagulation, which we generically call "damage." The "damage integral" $(\Omega)$ is given by

$$
\Omega=\int k d t
$$

where the damage rate is

$$
k=\frac{k_{\mathrm{b}} T}{h} \exp \left[\frac{\Delta S}{R}-\frac{\Delta H}{R T}\right] .
$$

In these equations, $k_{b}, h$, and $R$ are the Boltzmann, Planck, and gas constants, $T$ is temperature, and $\Delta S$ and $\Delta H$ are the entropy and enthalpy of the reaction. The undamaged fraction of the tissue is $f_{\mathfrak{u}}=$ $\exp (-\Omega)$, while the damaged fraction is $f_{\mathrm{d}}=1-f_{\mathrm{u}}$.

The chemical reactions responsible for tissue coagulation are endothermic. This is represented by an additive term to the tissue internal energy in the bioheat equation. The total internal energy is written: 


$$
E_{\text {int }}=C_{p} \Delta T+f_{d} E_{d}
$$

where the first term contains the usual heat capacity, $C_{p}$ (assumed constant) and $E_{d}$ in the second term is the energy per unit mass required for coagulation.

We also include temperature and damage effects on the blood perfusion, using the following formula:

$$
P=P_{0} f(T) \exp (-\Omega)
$$

where $P_{0}$ is the constitutive perfusion, $T$ is local temperature, $f(T)$ accounts for vessel dilation at slightly elevated temperatures and $\Omega$ is the damage integral. We specify $f(T)$ to be a linear function ranging from unity at $37^{\circ} \mathrm{C}$ to 4 at $42{ }^{\circ} \mathrm{C}$. Above $42^{\circ} \mathrm{C}$ it is constant. This expression [Eq. (3)] causes perfusion to increase 4 -fold as the temperature rises, but as coagulation develops it is reduced to zero by the damage factor.

The dynamic scattering coefficient was a linear combination of an undamaged and a damaged coefficient: $\mu_{\mathrm{s}}=\mu_{\mathrm{u}} f_{\mathrm{u}}+\mu_{\mathrm{d}} f_{\mathrm{d}}$. The absorption coefficient was fixed at $\mu_{\mathrm{a}}$.

\subsection{Problem Geometry.}

Our models consider an idealized 2-dimensional cylindrically symmetric domain $3 \mathrm{~cm}$ in length by $2 \mathrm{~cm}$ in radius, centered on the optical fiber. This domain is meant to represent the region near the diffusing fiber. A more accurate simulation would require 3-D modeling which is beyond the scope of this project. The fiber is placed on the axis $(r=0)$ so that the light enters the tissue in a $1 \mathrm{~cm}$ long by $0.09 \mathrm{~cm}$ radius cylinder at the center of the problem. We assume a constant laser emission energy per unit length along the $1-\mathrm{cm}$ region. Equally spaced spatial zones are used. The outer boundaries are transparent to laser light and reflecting to heat transport. In practice the boundaries are sufficiently far from the laser deposition and heated region, that they have very little influence on inner region of interest.

\subsection{Parameter Determination.}

We have chosen a set of standard parameters given in Table 1 . The laser wavelength is $810 \mathrm{~nm}$ and the optical constants are taken from the values for human prostate at $850 \mathrm{~nm} .^{2}$ We use the reduced scattering description in which the actual scattering coefficient $\left(\mu_{\mathrm{S}}\right)$ and anisotropy factor $(\mathrm{g})$ are replaced by an isotropic reduced scattering coefficient: $\mu_{\mathrm{s}}^{\prime}=(1-\mathrm{g}) \mu_{\mathrm{s}}$. We have found this approximation to be quite accurate and to save a lot of computer time. We assume that the fiber is highly scattering, but does not significantly absorb laser light. The thermal conductivity $(\kappa)$ and heat capacity $\left(C_{p}\right)$ of the tissue are taken to be the standard values for water, which is typical for prostate and other soft tissues. ${ }^{3}$ The standard blood perfusion rate is taken as $40 \mathrm{cc} / 100 \mathrm{~g} / \mathrm{min}$. Specific blood perfusion rates are not available for human prostate, but this is a typical value for dog prostate and other soft tissues. ${ }^{4}$ Damage rate coefficients, $\Delta S$ and $\Delta H$, were taken from fits to average data for whitening of several tissues: dog prostate, dog heart, and rat and pig liver. ${ }^{5}$ With these coefficients, the damage time scale $(1 / \mathrm{k})$ is about $0.1 \mathrm{~s}$ at $100^{\circ} \mathrm{C}$, the target temperature in the experiments. The standard value of the damage energy, $\mathrm{E}_{\mathrm{d}}$ is taken from differential scanning calorimetry measurements for several tissues such as rat tail tendon. 6,7 
Table 1. Standard parameter values and range of variation

\begin{tabular}{|l|r|r|r|}
\hline parameter & standard value & minimum & maximum \\
\hline$\mu_{\mathrm{a}}$ (tissue) & $0.65 \mathrm{~cm}^{-1}$ & 0.1625 & 0.65 \\
\hline$\mu_{\mathrm{su}}{ }^{\prime}$ (tissue) & $6.0 \mathrm{~cm}^{-1}$ & 1.5 & 6.0 \\
\hline$\mu_{\mathrm{Sd}}{ }^{\prime}$ (tissue) & $13.8 \mathrm{~cm}^{-1}$ & 1.5 & 13.8 \\
\hline$\mu_{\mathrm{a}}$ (fiber) & 0 & - & - \\
\hline$\mu_{\mathrm{s}}{ }^{\prime}$ (fiber) & $10 \mathrm{~cm}^{-1}$ & - & - \\
\hline$\kappa$ (tissue) & $6.09 \mathrm{mw} /\left(\mathrm{cm}^{\circ} \mathrm{C}\right)$ & - & - \\
\hline $\mathrm{C}_{\mathrm{p}}$ (tissue) & $4.2 \mathrm{~J} /\left(\mathrm{g}^{\circ} \mathrm{C}\right)$ & - & - \\
\hline$\kappa$ (fiber) & $15 \mathrm{mw} /\left(\mathrm{cm}^{\circ} \mathrm{C}\right)$ & - & - \\
\hline $\mathrm{C}_{\mathrm{p}}$ (fiber) & $4.2 \mathrm{~J} /\left(\mathrm{g}^{\circ} \mathrm{C}\right)$ & - & 200 \\
\hline $\mathrm{P}$ & $40 \mathrm{c} / 100 \mathrm{~g} / \mathrm{min}^{\prime}$ & 0 & - \\
\hline$\Delta \mathrm{S}$ & $68.2 \mathrm{cal} / \mathrm{deg} / \mathrm{mole}$ & - & - \\
\hline$\Delta \mathrm{H}$ & $45.79 \mathrm{kcal} / \mathrm{mole}$ & - & 300 \\
\hline$\Delta \mathrm{E}_{\mathrm{d}}$ & $50 \mathrm{~J} / \mathrm{g}$ & 0 & \\
\hline
\end{tabular}

\subsection{Parameter Variations}

Several input parameters were varied in the simulations in order to ascertain the sensitivity of the simulation results to both uncertainties and patient-to-patient variability of the values. Table 1 lists the minimum and maximum values taken for those parameters which were varied. These variations were guided by the range of values found in the literature and also by the range necessary to match the range in the patient heating data, discussed in $\S 4$.

\section{SIMULATION RESULTS}

\subsection{Method}

Each computer run spans $240 \mathrm{~s}$ of simulated time. A constant laser power of $10 \mathrm{~W}$ is maintained until the temperature at the end of the fiber reaches $100^{\circ} \mathrm{C}$. Then the laser is toggled on and off, keeping the temperature within a $5^{\circ} \mathrm{C}$ full range about $100^{\circ} \mathrm{C}$. This "thermostat" function is meant to simulate the temperature control system used in the actual experiments. In our simulations the "measured" temperature is averaged over 5 zones near the end of the fiber corresponding to a cylindrical volume of length $0.2 \mathrm{~cm}$ and radius $0.09 \mathrm{~cm}$, in order to reduce noise associated with the Monte-Carlo laser transport method. The temperature is sampled every time step, which is set at $1 / 2 \mathrm{~s}$. 


\subsection{Standard Simulation.}

We first describe the results of a simulation ("run") with the standard parameter values given in Table 1. This run is labeled $6 \mathrm{~d}$ in Table 2 , which summarizes all of the runs. The time dependence of the temperature at the end of the fiber, the time-integrated laser-delivered energy and the coagulated tissue volume are shown in Figure 1. The temperature rises to $100^{\circ} \mathrm{C}$ in $53 \mathrm{~s}$, at which time the thermostat kicks-in. We designate the time at which the temperature first reaches $100^{\circ} \mathrm{C}$ as $\mathrm{t}_{100}$. Oscillations of the temperature are seen after $t_{100}$. The energy increases linearly until $t_{100}$ (constant power) and then rolls off, increasing in a step wise manner with a smaller average power. The total energy delivered during $240 \mathrm{~s}$ is $1.54 \mathrm{~kJ}$, corresponding to an average power of $6.4 \mathrm{~W}$.

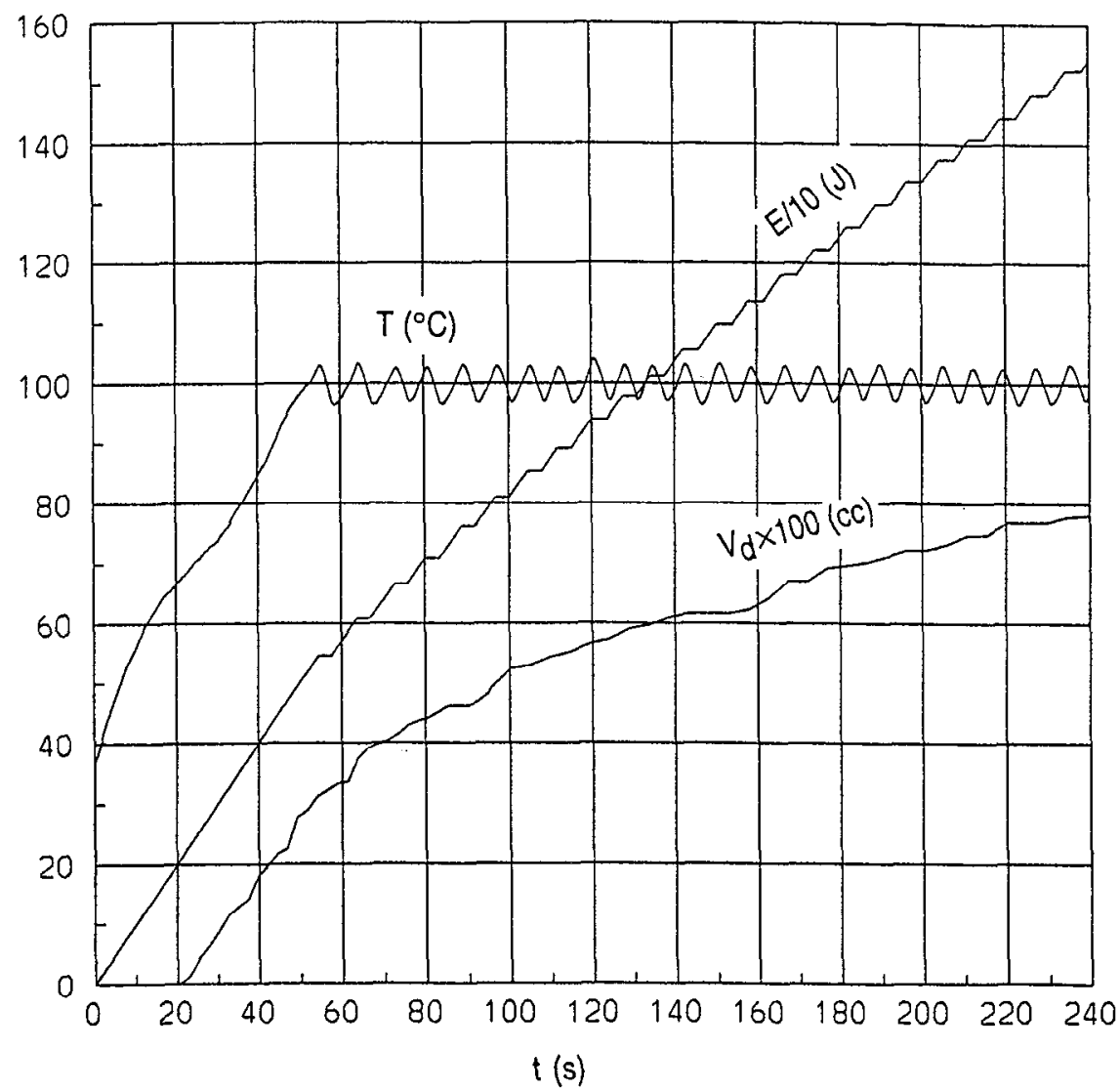

Figure 1. Temperature $(T)$, time-integrated laser delivered energy $(E)$, and damage volume $\left(V_{d}\right)$ versus time. Data are for the standard run( 6d). The thermostat function kicks in at $53 \mathrm{~s}$.

The 2-D distributions of temperature and damage at $60 \mathrm{~s}$ are shown in Figures $2 \mathrm{a}$ and $\mathrm{b}$. The temperature distribution is broader than the light distribution (not shown). It gets broader with time as shown by Figure 3a. Both the larger breadth of temperature distribution and the growth of the heated region with time result from thermal conduction. The extent of the damaged region also grows with time as shown in Figure $3 \mathrm{~b}$. This growth is due both to thermal conduction and to the time accumulation of damage illustrated in the damage integral [Equation 1(a)]. We define the damage volume $\left(V_{d}\right)$ as that volume having $\Omega$ greater than unity. It approximates the volume of tissue, which is expected to be coagulated during the laser irradiation. The time dependent growth of the damage volume is shown for the standard model in Figure 1. The damage volume grows from $0.33 \mathrm{cc}$ at $60 \mathrm{~s}$ to $0.78 \mathrm{cc}$ at $240 \mathrm{~s}$. 
Table 2. Main input parameters and results for all runs

\begin{tabular}{|c|c|c|c|c|c|c|c|c|}
\hline run & $\begin{array}{c}\mathrm{P} \\
\mathrm{cc} / 100 \mathrm{~g} \\
/ \mathrm{min} .\end{array}$ & $\begin{array}{c}\mu_{\mathrm{su}}^{\prime} \\
\mathrm{cm}^{-1}\end{array}$ & $\underset{\mathrm{cm}}{\mu_{\mathrm{a}}}$ & $\begin{array}{l}\mu_{\mathrm{sd}^{\prime}} \\
\mathrm{cm}^{-1}\end{array}$ & $\begin{array}{c}\Delta \mathrm{E}_{\mathrm{d}} \\
\mathrm{J} / \mathrm{g}\end{array}$ & $\begin{array}{c}t_{100} \\
s\end{array}$ & $\begin{array}{l}\mathrm{V}_{\mathrm{d}} \\
\mathrm{cc}\end{array}$ & $\begin{array}{c}\mathrm{E} \\
\mathrm{kJ}\end{array}$ \\
\hline $6 a$ & 80 & 6.0 & 0.650 & 13.8 & 50 & 76 & 0.58 & 1.83 \\
\hline $6 b$ & 80 & 6.0 & 0.650 & 13.8 & 0 & 70 & 0.59 & 1.78 \\
\hline$\overline{6 c}$ & 80 & 6.0 & 0.325 & 13.8 & 50 & 250 & 0.35 & 2.40 \\
\hline $6 \mathrm{~d}$ & 40 & 6.0 & 0.650 & 13.8 & 50 & 53 & 0.78 & 1.54 \\
\hline $6 e$ & 40 & 6.0 & 0.325 & 13.8 & 50 & 136 & 0.82 & 2.12 \\
\hline $6 f$ & 80 & 6.0 & 0.488 & 13.8 & 50 & 129 & 0.57 & 2.12 \\
\hline $6 g$ & 40 & 6.0 & 0.488 & 13.8 & 0 & 67 & 0.82 & 1.68 \\
\hline $6 \mathrm{~h}$ & 40 & 6.0 & 0.650 & 13.8 & 0 & 48 & 0.80 & 1.50 \\
\hline $6 i$ & 120 & 6.0 & 0.650 & 13.8 & 0 & 115 & 0.46 & 2.07 \\
\hline $6 j$ & 120 & 6.0 & 0.650 & 13.8 & 50 & 122 & 0.45 & 2.10 \\
\hline $6 \mathrm{k}$ & 40 & 6.0 & 0.650 & 6.0 & 50 & 72 & 0.95 & 1.85 \\
\hline 61 & 40 & 3.0 & 0.650 & 3.0 & 50 & 153 & 0.91 & 2.24 \\
\hline $6 \mathrm{~m}$ & 40 & 1.5 & 0.650 & 1.5 & 50 & 250 & 0.65 & 2.40 \\
\hline $6 n$ & 160 & 6.0 & 0.650 & 13.8 & 50 & 202 & 0.33 & 2.35 \\
\hline 60 & 40 & 6.0 & 0.650 & 13.8 & 100 & 59 & 0.77 & 1.58 \\
\hline $6 p$ & 40 & 6.0 & 0.650 & 13.8 & 150 & 66 & 0.74 & 1.64 \\
\hline $6 q$ & 40 & 6.0 & 0.650 & 13.8 & 300 & 84 & 0.67 & 1.77 \\
\hline $6 r$ & 0 & 6.0 & 0.650 & 13.8 & 300 & 63 & 1.13 & 1.46 \\
\hline $6 s$ & 0 & 6.0 & 0.650 & 13.8 & 0 & 35 & 1.70 & 1.13 \\
\hline $6 \mathrm{t}$ & 40 & 3.0 & 0.650 & 6.9 & 50 & 98 & 0.84 & 1.97 \\
\hline $6 u$ & 40 & 1.5 & 0.650 & 3.5 & 50 & 200 & 0.74 & 2.37 \\
\hline $6 \mathrm{v}$ & 40 & 6.0 & 0.650 & 13.8 & 600 & 122 & 0.59 & 2.00 \\
\hline $6 w$ & 0 & 6.0 & 0.650 & 13.8 & 50 & 39 & 1.56 & 1.20 \\
\hline $6 x$ & 200 & 6.0 & 0.650 & 13.8 & 50 & 250 & 0.19 & 2.40 \\
\hline $6 y$ & 40 & 6.0 & 0.488 & 13.8 & 50 & 76 & 0.80 & 1.75 \\
\hline $6 z$ & 40 & 6.0 & 0.162 & 13.8 & 50 & 250 & 0.19 & 2.40 \\
\hline
\end{tabular}




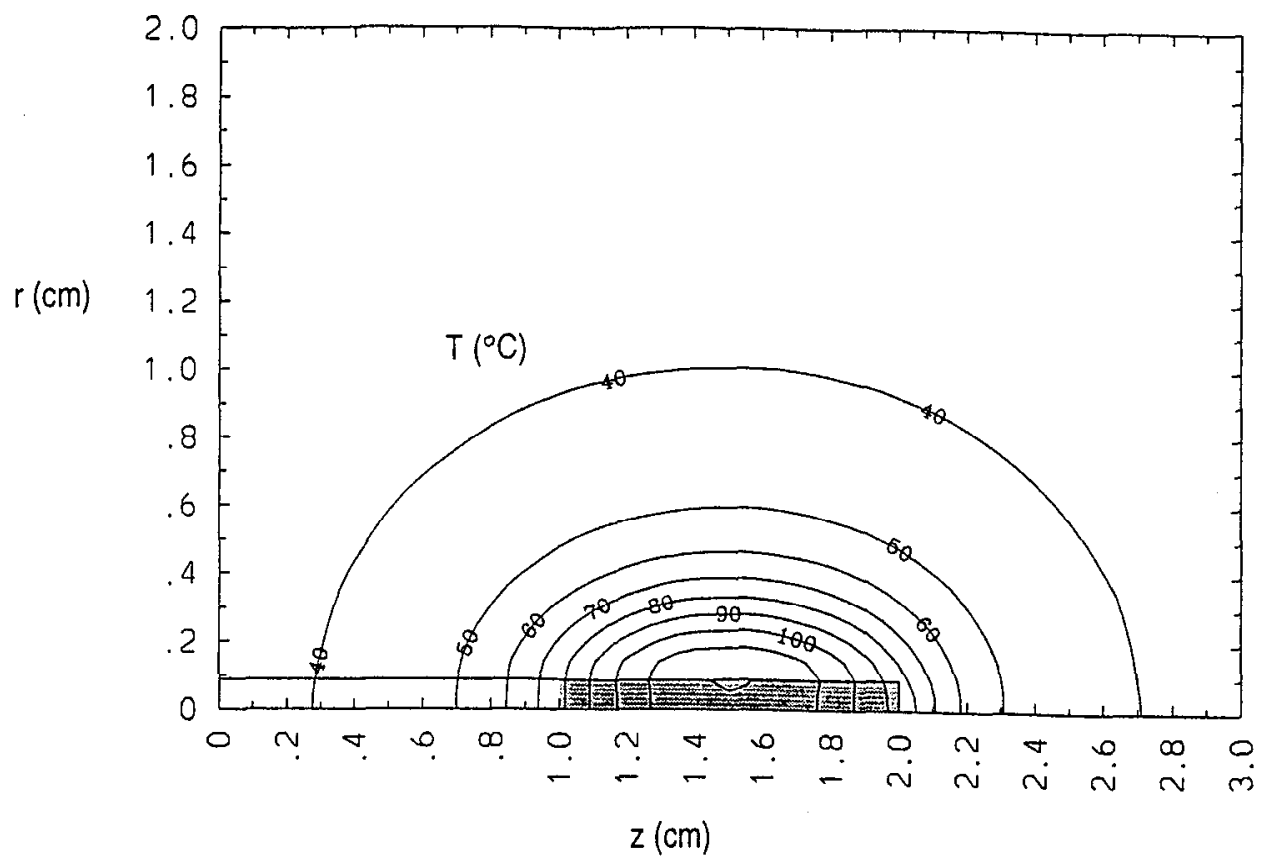

Figure 2a. Temperature distribution at $60 \mathrm{~s}$ for the standard run (6d).

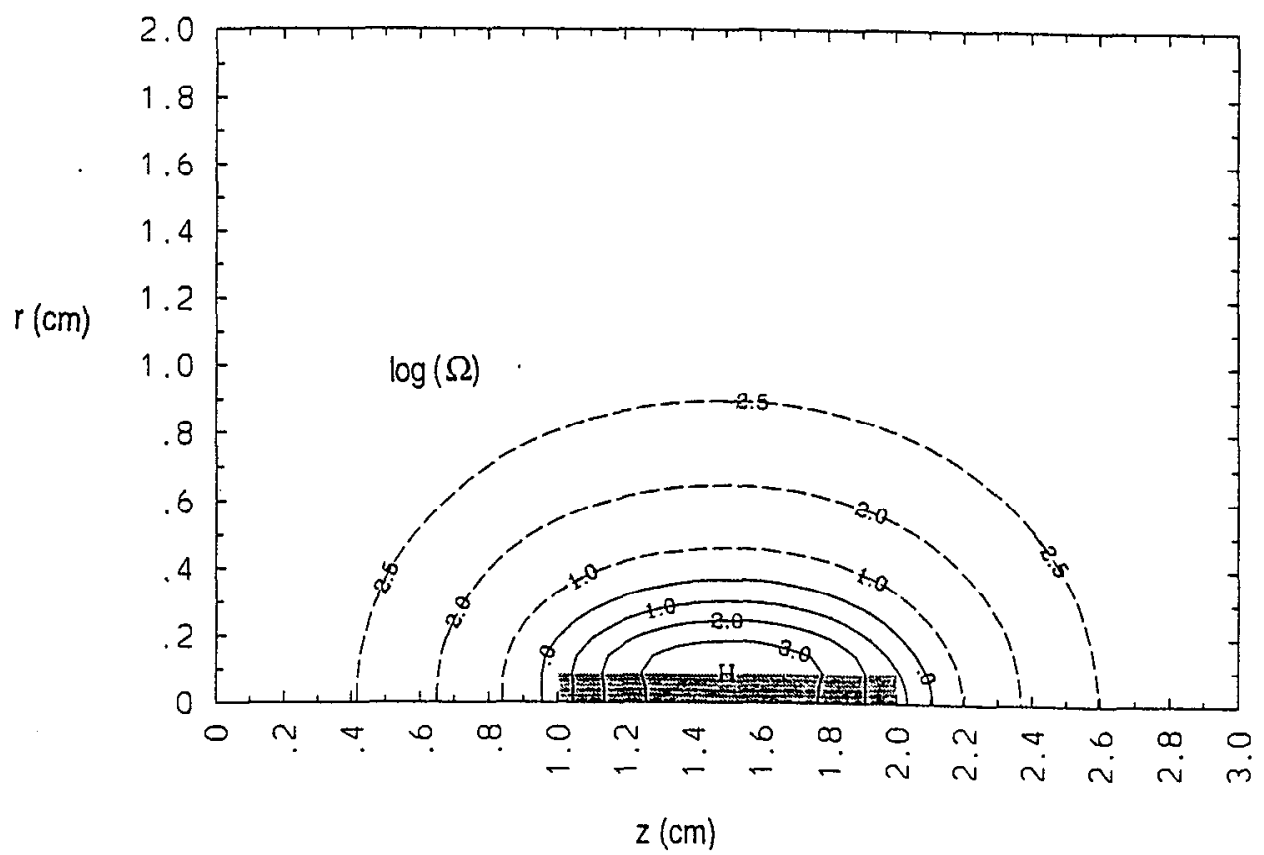

Figure $2 \mathrm{~b}$. Distribution of the common logarithm of the damage integral $(\Omega)$ at $60 \mathrm{~s}$ for the standard run (6d). Dashed contours indicate negative values of $\log _{10}(\Omega)$, while solid contours indicate positive values. 


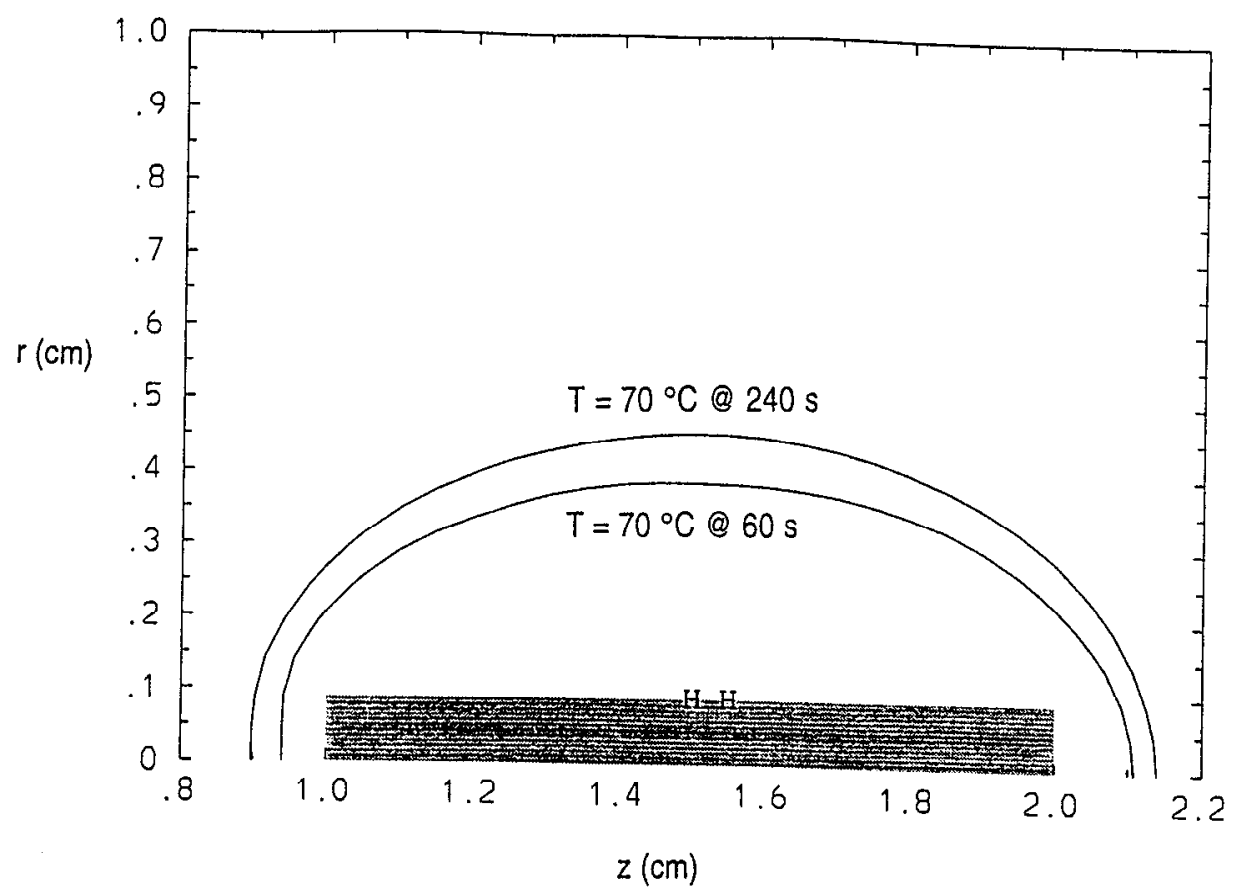

Figure 3a. Contours of $\mathrm{T}=70^{\circ} \mathrm{C}$ at 60 and $240 \mathrm{~s}$ for the standard run (6d).

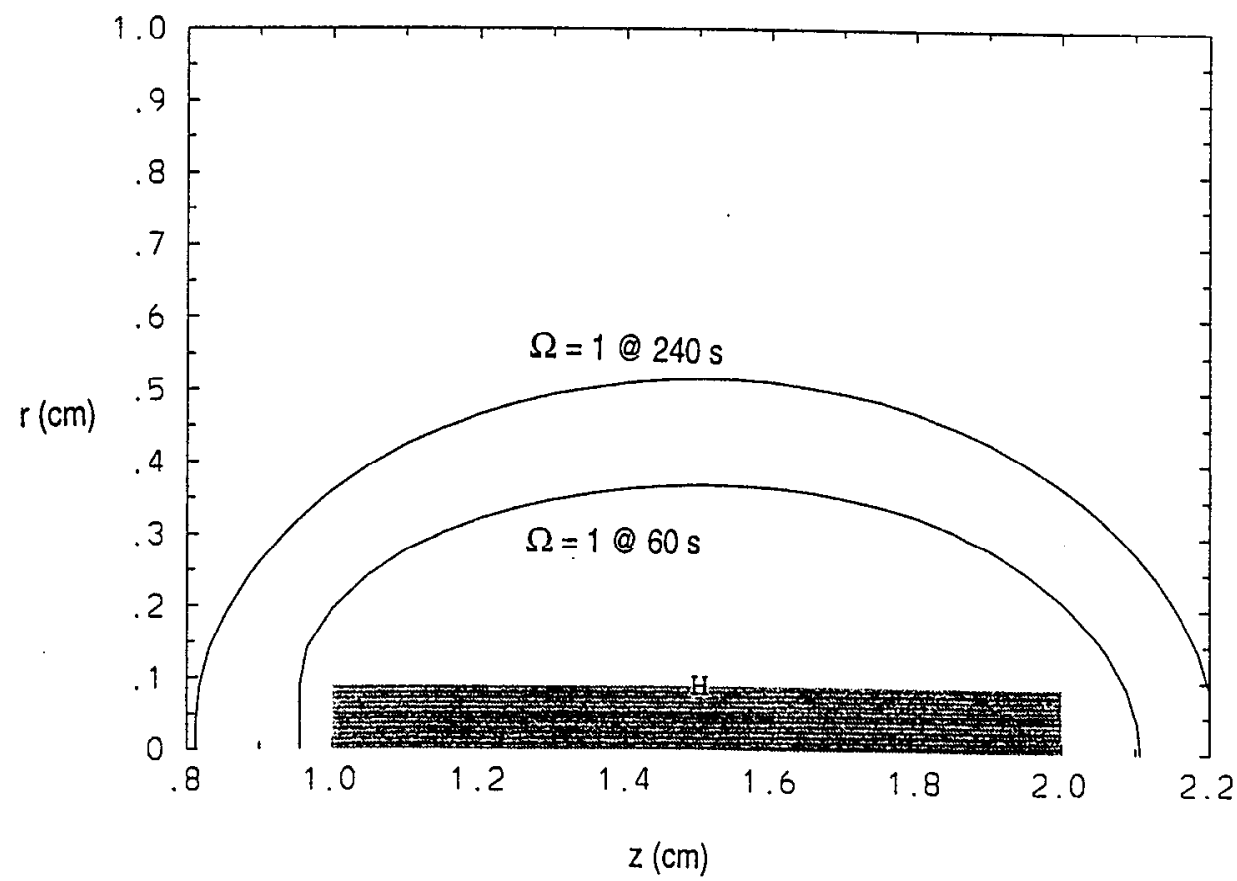

Figure $3 \mathrm{~b}$. Contours of $\Omega=1$ at 60 and $240 \mathrm{~s}$ for the standard run (6d). 


\subsection{Results from Parameter Variation.}

Since the $t_{100}$ value of $53 \mathrm{~s}$ for the standard run is small compared to the average patient value of $130 \mathrm{~s}$ (see $\S 4$ ), we consider a run with half the absorption coefficient: $\mu_{\mathrm{a}}=0.325 \mathrm{~cm}^{-1}$ (run 6e in Table 2 ). The $t_{100}$ value is $136 \mathrm{~s}$, more than twice the value for the standard model. Compared to standard model, the total energy delivered is $40 \%$ larger and the damage volume is $5 \%$ larger. The absorption coefficient has a large effect on the heating time, but a small effect on the damage volume. This insensitivity of the damage volume to absorption coefficient is due to the temperature clamping at 100 ${ }^{\circ} \mathrm{C}$. The large influence of conduction and perfusion cooling at later times overrides the difference in light distribution between the two models.

We have completed a study varying several of the input parameters $\left(\mu_{\mathrm{a}}, \mu_{\mathrm{s}}{ }^{\prime}, \mathrm{P}\right.$, and $\left.\Delta \mathrm{E}_{\mathrm{d}}\right)$. The results are presented in Table 2 . In Figures $4 \mathrm{a}-\mathrm{d}$ we illustrate the variation in the results with independent variations of the four parameters.

Variations in the absorption coefficient $\left(\mu_{\mathrm{a}}\right)$ have a large effect on $t_{100}$, but a relatively small effect on the damage volume as illustrated in Figure $4 \mathrm{a}$ and discussed above.

Variations in the scattering coefficient $\left(\mu_{\mathrm{S}}{ }^{\prime}\right)$ have an effect qualitatively similar to variations in the absorption coefficient, as can be seen by comparing Figs. 4a and $4 \mathrm{~b}$. This can be understood by noting the analytical expression for the effective absorption coefficient in a scattering dominated medium $\left(\mu_{\mathrm{s}^{\prime}}>>\mu_{\mathrm{a}}\right): \mu_{\mathrm{a}} \mathrm{eff}=\left(3 \mu_{\mathrm{a}} \mu_{\mathrm{s}}\right)^{1 / 2}$. This expression characterizes the absorbed energy distribution. Because the dependence of $\mu_{\mathrm{a}}$ eff on $\mu_{\mathrm{a}}$ and $\mu_{\mathrm{s}}$ ' is similar, a variation in either parameter has a similar effect of $t_{100}$.

Increasing the perfusion rate $(P)$ leads to larger values of $t_{100}$, and $E$, and smaller $V_{d}$ as shown in Figure $4 c$. The dependencies are all fairly strong. These trends reflect the increasing sink of energy created by the perfusion.

The effect of varying the endothermic energy $\left(E_{d}\right)$ of the damage reaction is shown in Figure $4 \mathrm{~d}$. As with perfusion, this process represents a sink of energy; therefore $t_{100}$ and $E$ increase with $E_{d}$, while $\mathrm{V}_{\mathrm{d}}$ decreases. The endothermic effect has not been included in previous calculations of this type. It appears to be an important, but not overwhelming effect. The nominal value of $E_{d}=50 \mathrm{~J} / \mathrm{g}$ results in a $10 \%$ increase in $t_{100}$ compared to the case with $E_{d}=0$. It takes a very large value of $E_{d}$ to make a large difference in $t_{100}$.

Figure 5 shows the variation of the damage volume for all 26 runs, plotted against $t 100$. This is of interest since $V_{d}$ is the main prediction of the simulations which has clinical interest, both because it represents the desired outcome of the therapy and because it cannot be easily measured in patients. The primary measured quantity in the clinical experiments is $t_{100}$, as discussed in $\S 4$. We note the general trend of $\mathrm{V}_{\mathrm{d}}$ to decrease with increasing $\mathrm{t}_{100}$. The maximum $\mathrm{V}_{\mathrm{d}}$ seen in our parameter study was $1.7 \mathrm{cc}$ occurring for a run having $t_{100}=36 \mathrm{~s}$, while the minimum was $0.19 \mathrm{cc}$ for 2 runs which had $\mathrm{t}_{100}>240 \mathrm{~s}$. 
(a)

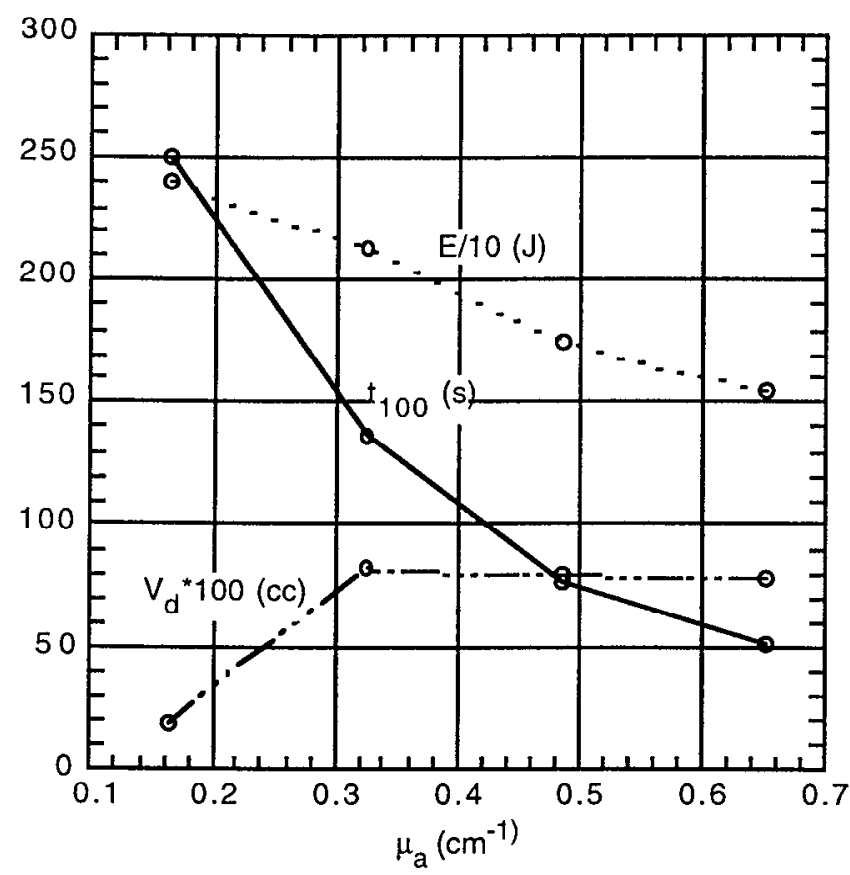

(c)

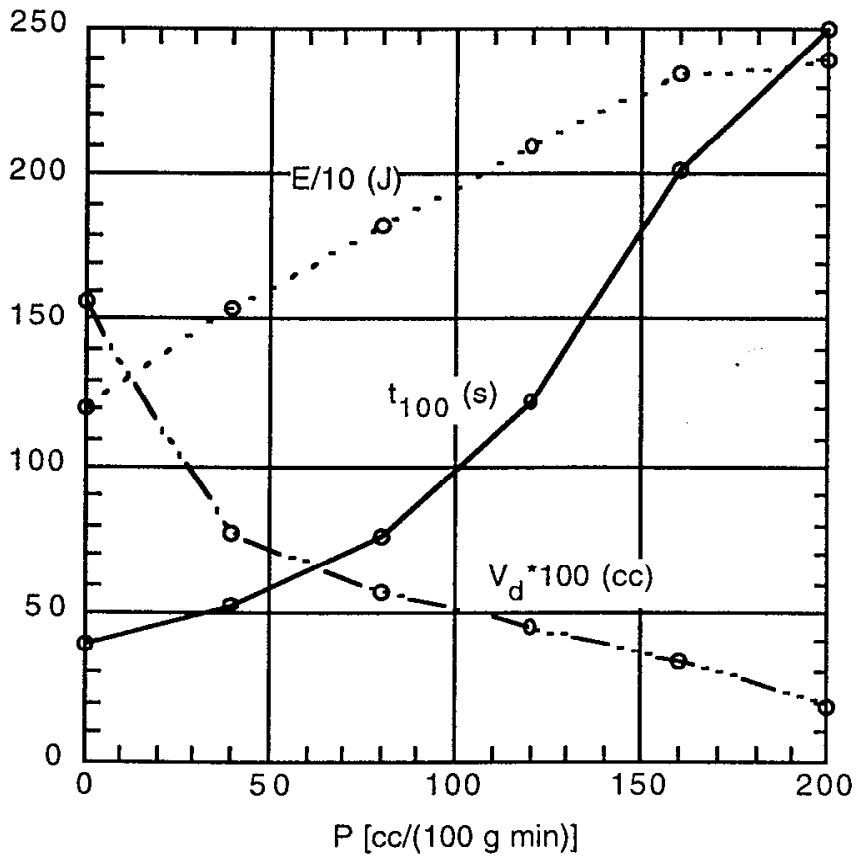

(b)

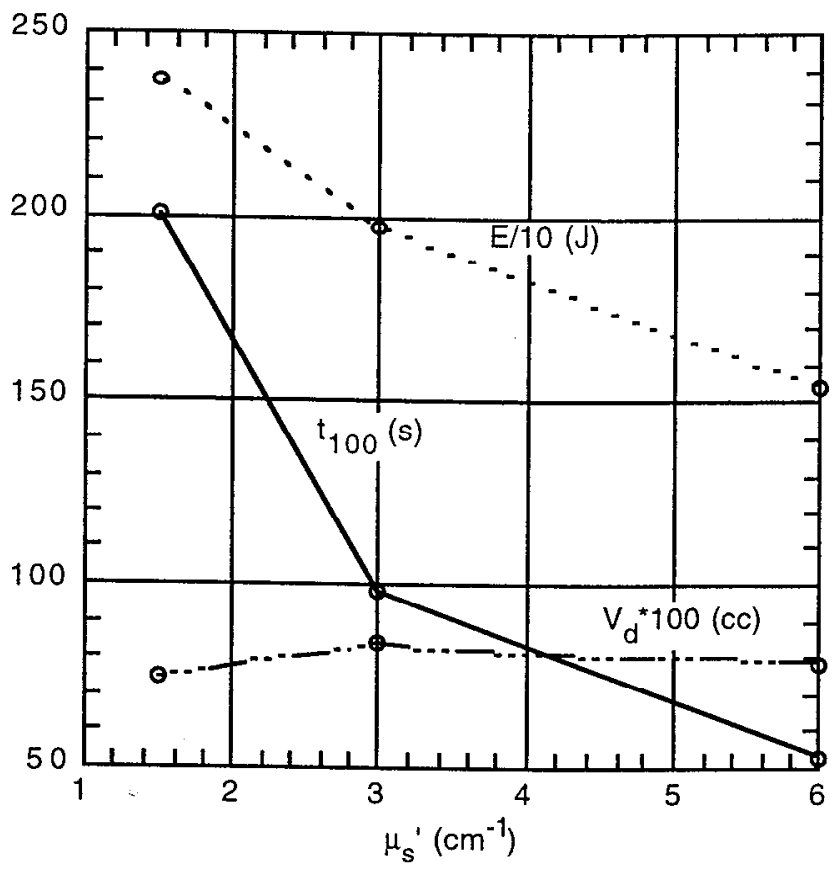

(d)

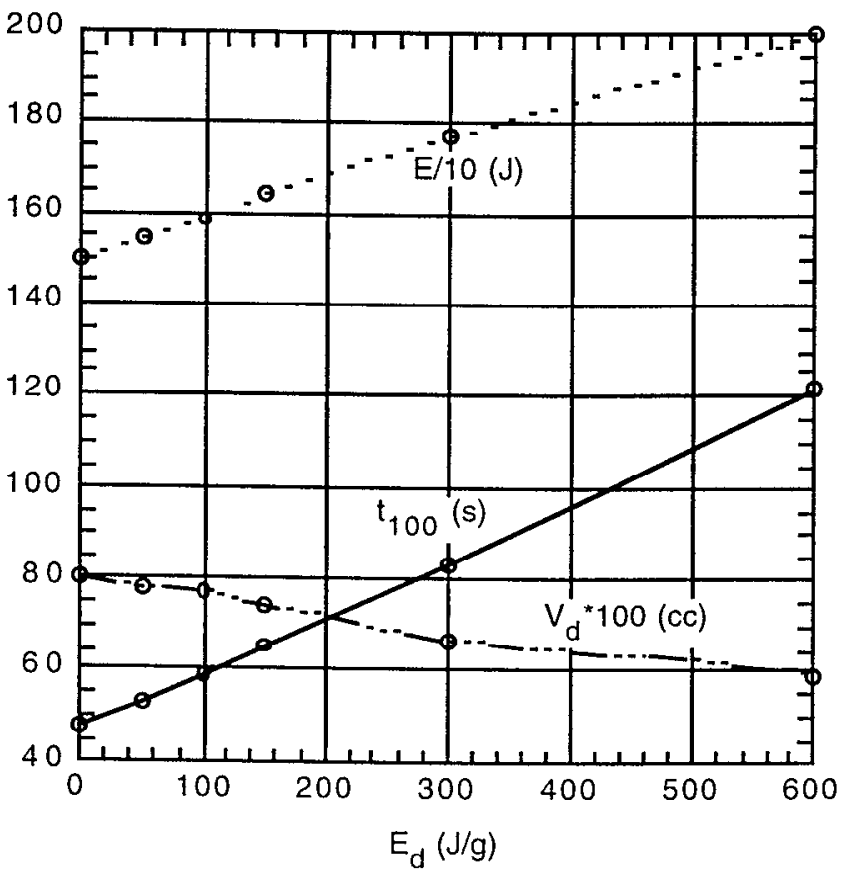

Figure 4a-d. Time-to- $100^{\circ} \mathrm{C}\left(\mathrm{t}_{100}\right)$, absorbed energy $(\mathrm{E})$ and damage volume $\left(\mathrm{V}_{\mathrm{d}}\right)$ versus absorption coefficient $\left(\mu_{\mathrm{a}}\right)$, reduced scattering coefficient $\left(\mu_{\mathrm{s}}{ }^{\prime}\right)$, blood perfusion rate $(\mathrm{P})$, and endothermic energy of tissue damage reaction $\left(\mathrm{E}_{\mathrm{d}}\right)$. Models which did not reach $100^{\circ} \mathrm{C}$ in $240 \mathrm{~s}$ are plotted at $250 \mathrm{~s}$. 


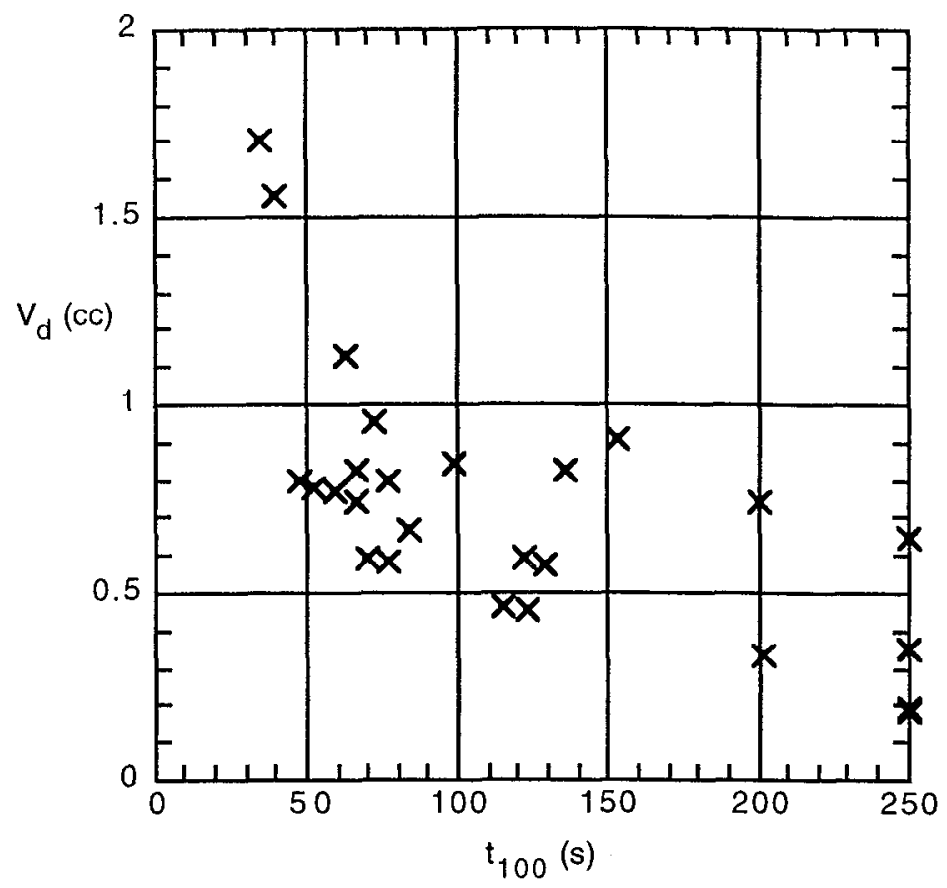

Figure 5. Damage volume $\left(\mathrm{V}_{\mathrm{d}}\right)$ versus time-to- $100{ }^{\circ} \mathrm{C}\left(\mathrm{t}_{100}\right)$ for all 26 models. Models which did not reach $100^{\circ} \mathrm{C}$ in $240 \mathrm{~s}$ are plotted at $250 \mathrm{~s}$.

\section{COMPARISON TO CLINICAL DATA}

Data were obtained from trials of the Indigo Medical Inc. system on 10 patients. The data consist of time dependent temperature and power measurements. Each patient received several (up to 13) $240 \mathrm{~s}$ doses of laser light at various placements of the fiber within the prostate. The temperature was monitored at a position near the fiber tip by an optical technique. During each dose, the laser power was initially set at either 10 or $15 \mathrm{~W}$. After the monitored temperature reached $100^{\circ} \mathrm{C}$, the laser power was controlled to maintain the temperature as close to $100^{\circ} \mathrm{C}$ as possible. Figure 6 shows several temperature datasets for an initial power of $10 \mathrm{~W}$.

In comparing the simulations to the clinical data we concentrate on the $\mathrm{t}_{100}$ values for the $10 \mathrm{~W}$ cases. The experimental data is summarized in Figure 7 as a histogram of the number of occurrences of doses with various values of $\mathrm{t}_{100}$. This figure includes 20 separate doses. Not included are an additional 15 doses in which the temperature did not reach $100^{\circ} \mathrm{C}$ in $240 \mathrm{~s}$. The data shown in Figure 7 have an average value of $\mathrm{t}_{100}=130 \mathrm{~s}$, and a range of $45 \mathrm{~s}$ to $220 \mathrm{~s}$. 


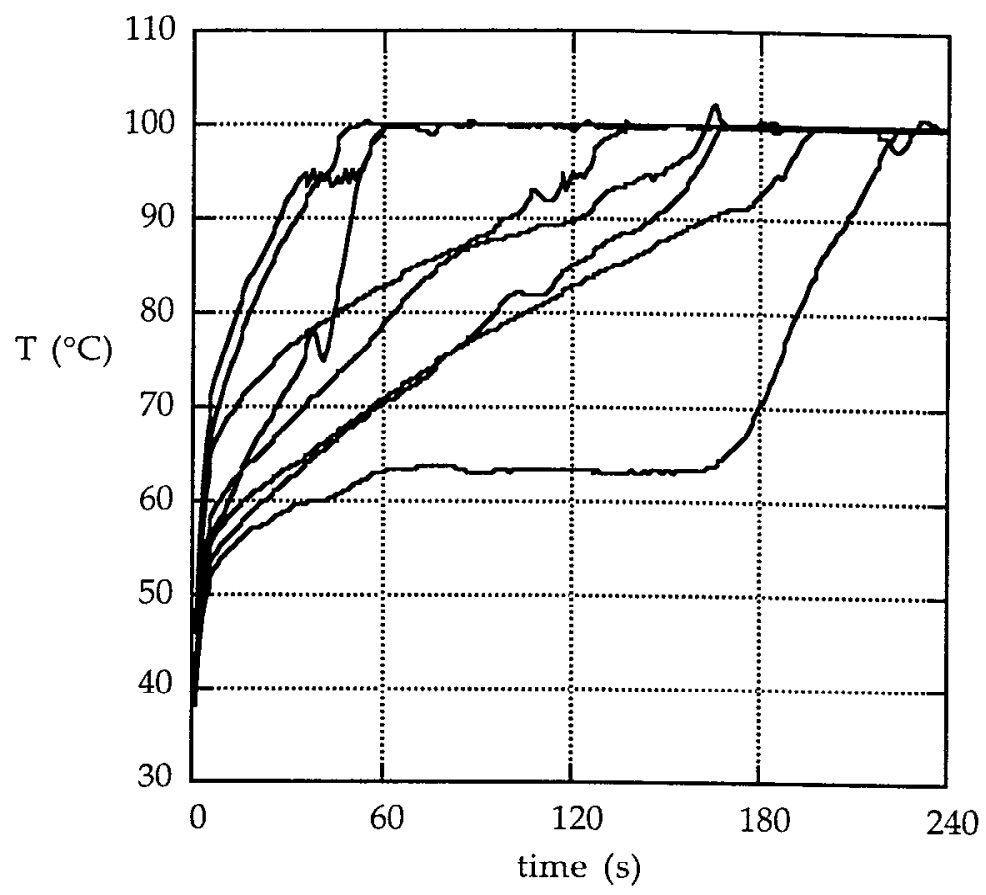

Figure 6. Representative temperature curves for clinical trial of the $\mathrm{BPH}$ laser system.

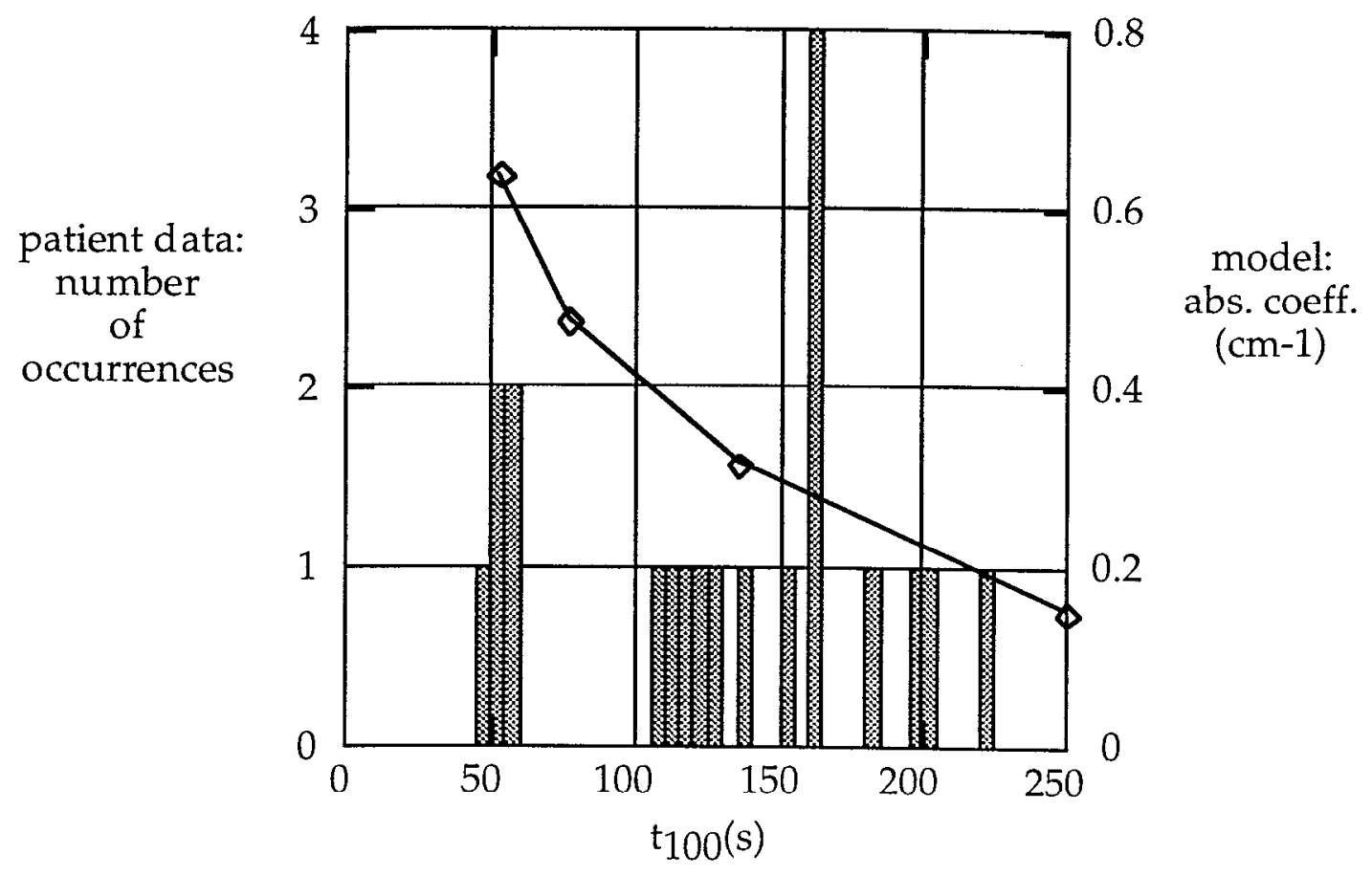

Figure 7. Histogram of distribution of time-to- $100^{\circ} \mathrm{C}\left(\mathrm{t}_{100}\right)$ from the $10 \mathrm{~W}$ clinical data. Only doses in which $100{ }^{\circ} \mathrm{C}$ was reached within $240 \mathrm{~s}$ are shown. The solid curve gives simulated $t_{100}$ plotted on the horizontal axis versus the absorption coefficient on the right vertical axis. 
Comparison of the simulations to the data suggests values of the model parameters which are required to give agreement. To reproduce the average value of $t_{100}$ (excluding those which do not reach $100^{\circ} \mathrm{C}$ ) we consider simple one parameter excursions from the standard values (see Table 1). Using linear interpolations in Figures $4 \mathrm{a}$ through $4 \mathrm{~d}$, we have found the parameter values necessary to achieve $t_{100}$ $=130 \mathrm{~s}$ and the associated damage volume $\left(\mathrm{V}_{\mathrm{d}}\right)$ calculated at $240 \mathrm{~s}$. These results are listed in Table 3 . Of course, variations of several parameters could be invoked to match the average $t_{100}$, as well. We see that the most effective parameter is $\mu_{\mathrm{a}}$. In other words, a smaller excursion in $\mu_{\mathrm{a}}$ from the standard value is needed to reproduce the measured $t_{100}$ compared to the other parameters which were varied. The sensitivity to $\mu_{\mathrm{s}}^{\prime}$ is similar, but somewhat weaker than to $\mu_{\mathrm{a}}$. The sensitivity to $\Delta \mathrm{E}_{\mathrm{d}}$ is the least: a very large excursion ( $>12$ times) is needed to reproduce the average $t_{100}$. When varying either $\mu_{\mathrm{a}}$ or $\mu_{\mathrm{s}}^{\prime}$ to achieve the measured $\mathrm{t}_{100}$, the damage volume is about the same: $0.81 \mathrm{cc}$, and also very similar to that for the standard case $(0.78 \mathrm{cc})$. The variation of perfusion to achieve the measured $\mathbf{t}_{100}$ is accompanied by a larger change in damage volume: it is reduced to about $1 / 2$ of the standard value. The sensitivity of the damage volume to changes in $\Delta \mathrm{E}_{\mathrm{d}}$ is intermediate.

Table 3. Parameter variations necessary to achieve measured $t_{100}$

\begin{tabular}{|c|c|c|c|}
\hline parameter & $\begin{array}{c}\text { value to } \\
\text { achieve } \\
\mathrm{t}_{100}=130 \mathrm{~s}\end{array}$ & $\begin{array}{l}\text { value } \\
\text { relative to } \\
\text { standard }\end{array}$ & $\begin{array}{l}\mathrm{V}_{\mathrm{d}} \\
(\mathrm{cc})\end{array}$ \\
\hline$\mu_{\mathrm{a}}$ & 0.34 & 0.52 & 0.81 \\
\hline$\mu_{\mathrm{s}}^{\prime}$ & 2.52 & 0.42 & 0.81 \\
\hline$P$ & 123 & 3.1 & 0.44 \\
\hline $\mathrm{E}$ & $>600$ & 12 & $<0.44$ \\
\hline
\end{tabular}

To address the range in $t_{100}$ seen in the patient data (from $45 \mathrm{~s}$ to greater than $240 \mathrm{~s}$ ), a wider range of parameter variations must be invoked. Such parameter excursions are summarized in Table 4 . The damage volume associated with these parameter excursions range from $0.19 \mathrm{cc}$ up to $1.15 \mathrm{cc}$. These input parameter variations, and the variations in predicted damage volume may be characteristic of the actual patient variability.

Table 4. Parameter variations corresponding to range in measured $t_{100}$

\begin{tabular}{|l|r|r|r|r|}
\hline parameter & $\begin{array}{r}\text { value to } \\
\text { achieve } \\
\mathrm{t}_{100}=45 \mathrm{~s}\end{array}$ & \multicolumn{1}{|c|}{$\begin{array}{c}\mathrm{V}_{\mathrm{d}} \\
(\mathrm{cc})\end{array}$} & $\begin{array}{c}\text { value to } \\
\text { achieve } \\
\mathrm{t}_{100}>240 \mathrm{~s}\end{array}$ & $\begin{array}{c}\mathrm{V}_{\mathrm{d}} \\
(\mathrm{cc})\end{array}$ \\
\hline$\mu_{\mathrm{a}}$ & 0.67 & 0.75 & 0.16 & 0.19 \\
\hline$\mu_{\mathrm{S}}{ }^{\prime}$ & 6.4 & 0.75 & 1.5 & 0.74 \\
\hline $\mathrm{P}$ & 20 & 1.15 & 200 & 0.19 \\
\hline $\mathrm{E}$ & $(0)$ & 0.79 & $>600$ & $(<0.59)$ \\
\hline
\end{tabular}




\section{CONCLUSIONS}

We draw several conclusions from comparing the simulations to the clinical data:

1. The standard run predicts a significantly faster initial heating than the average of the clinical data: simulated $t_{100}=53 \mathrm{~s}$ versus measured $t_{100}=130 \mathrm{~s}$. The standard run uses the best a-priori guess at the various parameters of the problem (see Table 1). However, it is recognized that many of the parameter determinations are quite uncertain and may also be expected to vary from patient to patient. Therefore, it is natural to consider variations in the input parameters to see if a better match to the clinical data is found.

2. Variations in several of the input parameters indicate that a good match to the clinical heating rate as characterized by $t_{100}$ can be easily achieved. The most likely parameters to be altered are the light transport coefficients and the perfusion. Decreasing either $\mu_{\mathrm{a}}$ or $\mu_{\mathrm{s}}$ ' by about a factor of 2 , or increasing perfusion by a factor of 3 give good agreement between the simulations and the data. These variations at constant $t_{100}$ produce a variation of $V_{d}$ by a factor of about 2 .

3. The range in patient $t_{100}$ can be explained by a reasonable range in input parameters.

4. The trend of decreasing $V_{d}$ with increasing $t_{100}$ seen in Figure 7 is also expected to represent a real trend in patients. This trend may be useful in refining the dose protocol to produce better control of the coagulated regions. To improve such predictions, and thereby to achieve a better control of the coagulated volume, it would be desirable to have a closer coupling between experiment and modeling. For example, the direct measurement of some of the input parameters to the model, such as $\mu_{\mathrm{a}}{ }^{\prime} \mu_{\mathrm{s}}{ }^{\prime}$, and $P$ would better constrain the models and thereby produce a tighter correlation between $t_{100}$ and $V_{d}$.

5. The large patient-to-patient variability in the data suggests that quantities in addition to temperature be monitored in order to control the coagulated volume. For example, in situ measurement of optical properties for each patient could improve the predictability of the coagulated volume.

In summary, we have developed a new computational model for photo-thermal therapy and applied it to the Indigo Medical Inc. BPH laser system. The model includes laser light transport with scattering and absorption, thermal transport, cooling due to blood perfusion, thermal tissue damage, and enthalpy of tissue damage. We found that a reasonable variation from a standard set of input data produces heating times, which match those measured in a group of patients. We suggest that the patient-to-patient variability can be explained by patient-to-patient variations in fundamental physical properties such as the optical coefficients. We predict thermally damaged volumes for each run and notice a general trend of decreasing damage volume with increasing heating time. However a range of damage volume occurs at any given heating time, due to the various parameter combinations which can be input to the model to produce a given heating time.

Further work should involve the measurement and input to the model of several specific data parameters such as optical coefficients, blood perfusion cooling, and coagulation rate coefficients. Comparison of damaged tissue volume, perhaps in animals, would be useful to further check the model. Extension of the models to 3-dimensions would be useful to pursue patient-specific treatment planning. With these improvements, a reliable prediction capability should be enabled. 


\section{ACKNOWLEDGMENTS}

This work was performed under the auspices of the U.S. Department of Energy by Lawrence Livermore National Laboratory under Contract W-7405-ENG-48, and supported by a Cooperative Research and Development Agreement between Lawrence Livermore and Indigo Medical. The authors thank D. Eder, D. Maitland, and M. Glinsky for contributions to the modeling effort.

\section{REFERENCES}

1. London, R. A., Glinsky, M. E., Zimmerman, G. B., Bailey, D. S., Eder D. C., and Jacques, S. L., "Laser-Tissue Interaction Modeling with LATIS," Applied Optics, 36, 9068 (1997).

2. Roggan, A. and Mueller, G., in "Laser Induced Interstitial Thermotherapy," Eds. Mueller, A. and Roggan, G., (SPIE: Bellingham, 1995), p. 114.

3. Orr, C.-S. and Eberhart, R. C., in "Optical-Thermal Response of Laser-Irradiated Tissue," Eds. Welch, A. J. and van Gemert, M. J. C. (Plenum: New York, 1995) p. 367.

4. Valvano, J. W., in "Optical-Thermal Response of Laser-Irradiated Tissue," (Plenum: New York, 1995) p, 445.

5. Jacques, S. private communication (1995).

6. McClain, P. E., and Wiley, E. R., J. Bio. Chem., 247, 692 (1972).

7. Miles, C. A., Burjanadze, T. V., and Bailey, A. J., J. Mol. Bio., 245, 438, (1995). 